\title{
$\square$ Peripheral vascular interventions: the perspective of an interventional cardiologist
}

\author{
Tomislav Šipić* \\ Clinic for Cardiovascular \\ Diseases Magdalena, \\ Krapinske Toplice, Croatia
}

KEYWORDS: peripheral vascular intervention, interventional cardiologist, vascular surgery. CITATION: Cardiol Croat. 2018;13(1-2):64. | https://doi.org/10.15836/ccar2018.64

*ADDRESS FOR CORRESPONDENCE: Tomislav Šipić, Magdalena Klinika za kardiovaskularne bolesti, Ljudevita Gaja 2, HR-49217 Krapinske Toplice, Croatia. / Phone: +385-91-5603-249 / E-mail: tomislavsipic2@gmail.com ORCID: Tomislav Šipić, https://orcid.org/0000-0001-8652-4523

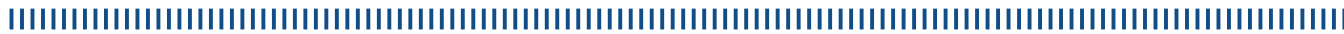

In the recent years, the cardiovascular patient became the focus of cardiovascular experts. Because the vessels in our body are made of the same material, the vascular problem could emerge from head to toe, so it is logical that, in the best interest of patient, the decision how to optimally treat the cardiovascular patient is often made by the team of experts - interventional cardiologists, vascular surgeons, interventional radiologists, anesthesiologists and sometimes many others expert. Some patients require combination of interventional and surgical treatment. According to this, there is a lot of overlapping between the professions. It is obvious that one new profession is emerging - endovascular medicine. ${ }^{1}$

In last 7 years, in our institution, our peripheral vascular team ( 2 interventional cardiologists and vascular surgeon), performed more than 330 peripheral interventions (on femoral, iliac and subclavian arteries) and more then 50 endovascular aneurysm repair and thoracic endovascular aneurysm repair procedures. In this presentation we will show our work and results during the recent period and some thoughts considering the development of endovascular medicine.
RECEIVED:

January 30, 2018

ACCEPTED:

February 10, 2018

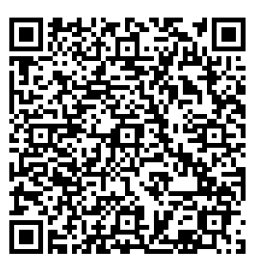

$\square$ Cardiologia Croatica 2018:13(1-2):64

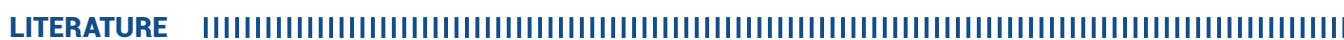
1. Ouriel K. Peripheral arterial disease. Lancet. 2001 0ct 13;358(9289):1257-64. https://doi.org/10.1016/\$0140-6736(01)06351-6 